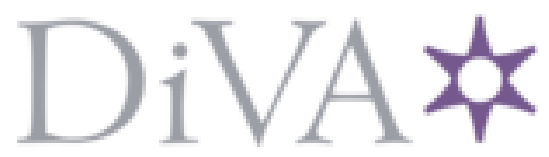

http://www.diva-portal.org

This is the published version of a paper published in social sciences.

Citation for the original published paper (version of record):

Andreasson, J. (2015)

Reconceptualising the Gender of Fitness Doping: Performing and Negotiating Masculinity through Drug-Use Practices.

social sciences, 4: 546-562

http://dx.doi.org/10.3390/socsci4030546

Access to the published version may require subscription.

N.B. When citing this work, cite the original published paper.

Permanent link to this version:

http://urn.kb.se/resolve?urn=urn:nbn:se:Inu:diva-45637 
Article

\title{
Reconceptualising the Gender of Fitness Doping: Performing and Negotiating Masculinity through Drug-Use Practices
}

\author{
Jesper Andreasson \\ Department of Sport Science, Linnaeus University, Kalmar SE-391 82, Sweden; \\ E-Mail: Jesper.andreasson@lnu.se; Tel.: +46-480-446-091 \\ Academic Editor: Martin J. Bull
}

Received: 28 May 2015 / Accepted: 3 August 2015 / Published: 6 August 2015

\begin{abstract}
This article analyses self-portrayals and gender constructions among Swedish male bodybuilders who are engaged in fitness doping. The empirical material comes from a larger ethnographic investigation into gym culture. The results show that there is a strong propensity to conform with particular gender fantasies that rests heavily on a binary understanding of gendered, doped bodies. However, this storyline does not apprehend the entire self-presentation of the analysed drug users. Negotiations and inclusive subversions of traditional gender norms are also expressed. For example, the narratives show how the use of performance-enhancing substances makes it possible for (heterosexual) men to approach, touch and express feelings of desire towards other men and their bodies. As such, this practice can be viewed as a contestation of hegemonic gender values, in which masculinity and fitness doping are detached from a quite heterosexist understanding, and turned into a symbolic world of homoerotic pleasure.
\end{abstract}

Keywords: masculinity; sexuality; health; body; fitness doping; gym culture

\section{Introduction}

As a dedicated, closed space for working on the body, the contemporary fitness gym has a long history, stretching all the way back to the gymnasium of the Greeks [1]. The modern roots of gym and fitness culture, however, are probably more in debt to what used to be called physical culture in the teachings of the forefathers of bodybuilding in the early part of 20th century [2]. Originally, this body (sub)culture was understood to be an almost exclusively masculine sphere. Furthermore, devoting time to building muscles and strengthening the body has historically been related to warfare, violence, and 
the building of nation-states - and is thus a practice that could be related to what Mosse [3] calls "the masculine stereotype".

The first wave of research on gym and fitness culture began mainly in the early 1990s, and the focus was on bodies, gender and identity [4-7]. Klein [7], for example, conducted a classical field study of bodybuilding, examining the creation of bodybuilding as a predominantly masculine subculture, and the tensions between it and mainstream societal norms and conventions. This study discusses narcissism, homophobia and hypermasculinity as institutionalised expressions within bodybuilding culture. However, it also illustrates contradictory and transgressive gender negotiations via bodybuilding, as for example when discussing how some bodybuilders, while formally condemning the behaviour, and self-identifying as emphatically heterosexual, chose to engage gay men in a range of more or less sexually explicit behaviours. Since the publication of Klein's study, the gym and fitness industry has changed considerably. What we see today is an increasing interest in research on gym and fitness culture. Recently, theorists have explored aspects of this phenomenon - such as corporeal ideals, gender transformations, illicit steroid use, and training techniques [8-12].

When it comes to the use of performance/image-enhancing substances (PES) in gym and fitness contexts, the usual position, in the literature, is that it is a subcultural phenomenon. Monaghan [13], for example, suggests that the social surroundings and the ideals promoted in this environment are key to understanding the presence of PES in gym and fitness culture (cf. [14]). It has even been suggested that the experimental use of different forms of testosterone in gym contexts stretches all the way back to the 1950s, when bodybuilders on the American west coast began to engage in this practice ([15], p. 84). Consequently, muscle-building — or more specifically, bodybuilding — in the gym has been associated with the use of PES for a long time (cf. [16,17]). Furthermore, men are overrepresented when it comes to the use of PES in connection with "pumping iron" [18-20]. Consequently, drug use in these contexts has predominantly, but not exclusively, been understood as due to men's desire to gain muscle mass and to construct a masculine identity [21-24]. Thualagant ([25], p. 415), however, concludes in a literature review that there is a need for a broader understanding of means of body enhancement, beyond merely the use of prohibited means to stimulate and accentuate what is perceived as a masculine body.

Consequently, this article aims to present a dissection and analysis of the construction of masculinity and drug-use practices in gym and fitness culture. As such the article has an underlying aim of challenging the gender politics of and more specifically the kind of masculinity that has been attached to the understanding of fitness doping. The purpose of the article is twofold: I am interested in how male PES users portray themselves and how their motivational trajectories that lead to doping can be understood; however, the main focus of this paper is on how different gender ideals and masculinities are constructed within this particular practice and context. Although narratives from female users are obviously also of great importance to understanding and challenging the gender politics associated with fitness doping, that analysis will be developed in another article. The present article focuses solely on the ways in which male users tend to frame and understand fitness doping in relation to gender. These objectives will be addressed using the following research questions:

RQ1: What kinds of self-portraits and understandings of the body and health appear in the narratives, and how do they relate to the use of PES? 
RQ2: In what ways is masculinity perceived and promoted through drug-use practices?

RQ3: How do the narratives relate to the cultural context in which they are presented?

In an attempt to answer these questions, the article is structured as follows: The next section will contain some theoretical considerations relevant to the analysis. Then I will explain the method and methodology on which the article is based. This will be followed by a discussion of the results, consisting of three parts that will deal with different positions and ways of performing masculinity in relation to fitness doping. In the conclusion, the results will be summarised and linked to theories of masculinity and fitness culture.

\section{Masculinities and the Gender Politics of Fitness Doping}

Theoretically, this article takes a social-constructionist approach. The article investigates how particular identities (masculinities) are expressed through drug-use practices, the pumping of iron, and social interaction in a bodybuilding context. In order to understand fitness doping in relation to gender it is necessary to dissect the whole phenomenon in relation to hegemonic masculinity [26,27]. This concept is used by Connell to describe relations of hierarchy between different masculinities, meaning that there are different ways of enacting manhood and learning how to become a man, and that some ways of doing masculinity are dominant while others are marginalised or subordinated.

In 1995, Connell defined hegemonic masculinity as a "configuration of gender practice that embodies the currently accepted answer to the problem of legitimacy of patriarchy" ([27], p. 77; see also [28]). Hence this concept indicates possible changes and transformations of gender. Different cultures and periods in history construct gender differently, and there is no static pattern of masculinity that can be found everywhere ([26], p. 10). Hegemony is tightly connected to patriarchy, and also understood as a strategy to legitimise a particular gender order, and a constellation of cultural ideals, institutional power, and politics [29]. However, the hegemonic position is always contestable; hence it is to be viewed as a dynamic concept that suggests possible transformations of gender relations and power structures.

In Inclusive Masculinities, Anderson [30] develops a different and to some extent highly challenging view of hegemonic masculinity. Anderson suggests that through different social and structural processes - for example, the lessening of homophobia — there has been a widening of the range of masculine identities possible to perform and embody. Although Anderson is aware that many contexts still define masculinity in opposition to femininity and homosexuality, he is quite hopeful when describing a scenario in which masculinity has gradually become more inclusive and accepting. Consequently, "inclusive masculinity" represents a theory that describes the emergence of an archetype of masculinity that undermines the principles of orthodox (read: hegemonic) masculine values, yet one that is also esteemed among male peers ([30], p. 93; cf. [31,32]). In the present article, different expressions and types of masculinity will be analysed in relation to drug-use practices and gym culture. The presentation will address both the adaptation to certain norms and categories, as well as more transgressive practices.

This article identifies particular structural transformations in the gender politics of fitness doping and masculinity. In the results section, the empirical material will be described, analysed 
and related to the theoretical background of Connell's theory of masculinity, and more recent critiques and developments of the concept of hegemony, and vice versa [33-35].

\section{Research Design and Methodology}

The article is a part of a larger ethnographic investigation into gym culture and drug-use practices that was conducted over several years, but mainly 2010-2013 [36]. The results are based on a study of highly dedicated gym-goers, mainly bodybuilders, with personal experience of PES. The fieldwork typically entailed observations, interviews, and informal conversations. Conducting ethnographic research can mean many things. Hammersley and Atkinson [37] describe ethnography as a collection of methods whereby the researcher in different ways and by different means aims to participate, more or less openly, in the other people's everyday lives (cf. [38,39]). Such an open and wide-ranging definition of research in the social sciences is close to the methodological point of departure of the research project on which this article is based. I have used various methods to establish relationships with PES users, aiming to describe, both theoretically and empirically, their everyday lives and perspectives on gender, doping, health, and the body.

Obviously the use of PES can mean many things, stretching from the use of protein supplement and amino acids to different kinds of steroids and more. This article focuses on users of prohibited substances. All informants interviewed have personal experiences of anabolic androgenic steroids. Several informants have also used, for example, human growth hormones to boost their performance.

Legislation regarding the use of PES varies. Unlike in many other European countries, Swedish legislation does not simply forbid the possession and distribution of doping substances, but also the presence of these substances in the body. Furthermore, in Sweden as well as internationally, governments and public health organisations conduct fairly comprehensive anti-doping campaigns. Consequently, gaining contact with and gaining the trust of PES users could be challenging. Various strategies were used in the project to identify and approach informants [40,41]. Firstly, certain organisations were helpful. For example, a Swedish organisation that helps ex-convicts re-integrate into society (KRIS) ${ }^{1}$, and Sweden's “anti-doping hotline" (Dopingjouren) ${ }^{2}$, assisted and provided some contacts. Secondly, Swedish fitness magazine Body was approached and agreed to a description of the research project appearing on their website, which netted a few informants. The most important source, however, was existing informants, who provided additional contacts for a second selection stage $(c f .[42,43])$.

One important aim of the sampling was to ensure variation among the informants regarding their training objectives, age, extent of PES experience, and ways of looking at the body and gender. As stated earlier this article focuses exclusively on male users. The aim of the sampling has been to gather data that answer the research questions in a nuanced way. A total of 19 men, between 19 and 62 years of age contributed their stories. Of these, a majority $(\mathrm{N}=14)$ were, when interviewed, still active users; others, however, claimed that they had stopped this practice $(\mathrm{N}=5)$.

1 KRIS is an association started by ex-criminals, with the basic idea to help people who are released from prison to stay away from crime and drugs, offering them an honest and drug free social network.

2 The Anti Doping Hot-Line is a Swedish nation-wide telephone consulting service, which you can call anonymously with questions about doping. The service is funded by the Ministry of Health and Social Affairs and the Ministry of Culture. 
The interviews were usually semi-structured, so the informants were able to speak freely, while at the same time I ensured a focus on specific themes (such as doping experience, understanding of the body, self-perception, gender, and health). As the informants were interviewed on more than one occasion, it was also possible to cover relevant topics that were missed in the first interview later on. Accordingly, the second, and sometimes third sets of interviews were conducted in a less structured manner. This approach also made it possible to accommodate more complex narratives and capture more detailed descriptions. A total of 52 interviews were conducted. I also spent approximately $150 \mathrm{~h}$ observing the informants, mainly in their training environments, but also joining them on trips to bodybuilding contests and visiting them in their homes. Observations were recorded daily with pen and paper or using an audio recorder. To secure confidentiality, informants were given pseudonyms.

When analysing the empirical material, I have firstly focused on the informants' perception of PES in relation to their self-understanding and gender. Secondly, I have focused on the cultural framing of this practice and how it can be understood in relation to different tendencies within a changeable fitness culture and gender order. The quotations and observations I present have been selected due to their ability to capture and describe both the subjective and the embodied experiences of PES, and the gender regimen in which this practice is constituted. In this sense, and although the analysis is mainly based on a narrative approach to the empirical material, I concur with Bourdieu and Wacquant [44] (1992), who suggest that personal narratives must be situated within a wider social and cultural context to be fully understood ( $c f$. [45]). In the next section, quotations that illustrate key narratives about PES users' ways of constructing masculinity and negotiating gender are presented and analysed.

\section{Results}

\subsection{Becoming a Man and the Risk of Losing it All}

In this first section of the results I will initially present some narratives of PES users that can be understood as rather traditional in relation to gender norms. This section thus reveals a historical continuity in the presentation and construction of a muscular masculinity, and shows how what Mosse [3] describes as the masculine stereotype are reproduced in contemporary fitness culture and through drug-use practices. This will be followed by two sections in which I will investigate different negotiating and inclusive gender configurations in relation to drug-use practices within gym culture.

One significant reason mentioned repeatedly regarding the informants' first involvement in muscle-building practices at the gym is the desire to become stronger, competitive, and to stand out in some way. Joseph (31-year-old youth teacher, married with one child) is a good representative of this approach. He started pumping iron at the age of 17 as he found it increasingly difficult to compete and perform physically among his peers. He felt insignificant, a low achiever in team sports, but in the gym setting this feeling changed and here he only had to compete against his own previous results. Joseph states:

"Well I guess there were some mean kids in my class who went on about me being a bit scrawny, or not very good, but I've never felt like I was totally bullied. (...) I think, what got me started was really, well more an inner ambition or feeling. I thought, I train hard dammit, but I'm never gonna be very good or successful in football, handball, or tennis, or whatever. But here, with the weights, I felt that this is a thing that I could do. I could be the 
master of my own destiny, so to speak. Back then you didn't know if you had a talent for it, but you kept on training" (Joseph).

Joseph's narrative can clearly be seen as an expression of how a young boy, in his quest to perform and "hold his ground" in relation to his peers, tries out different paths in life. Thus, Joseph put forward an ethos building on physical strength, masculinity and the importance of homosocial relations $[46,47]$. This kind of narrative is presented frequently, and another informant, Ian, sums it up as follows: "You always wanted to be the strongest (...). It's more fun if you notice that you are better than everyone else". This type of ethos is further developed in the following story, in which the use of PES is part of the equation, and is perceived almost as a necessary means of upholding a certain way of life and self-understanding.

"Without doping I feel more worn out, torn, and ill. With doping, I feel refreshed and rested. Anyway, there are always gonna be people who think they got it all figured out, right? They usually say things like, 'yeah but it's dangerous' and 'you'll be tempted to use it all the time'. And maybe there are these weak individuals who can't complete a course of treatment and don't know their limits and when to stay clean. But me, when I do treatment courses I always follow a pattern and a structure. I can always take a break, when I've been on for a certain number of weeks, and see that I've had enough for now. If I go over this limit, it is risky and I might destroy myself" (Robert, 37-year-old auto mechanic, engaged).

The key concepts in Robert's story are rationality and dominance. His desire to become stronger and develop a muscular body "that blows everyone away and shocks them" made him carefully consider what would be needed to achieve his goals. He entered into the world of steroids and acquired the necessary knowledge to manage and optimise the different courses of treatment in a "safe" and controlled manner. He distances himself from other users and the non-initiated, presenting himself as rational and in control. Consequently he is constructing something of a paradigmatic masculine narrative of a successful male career and rationality [48]. He presents a story (a paradigmatic narrative) about a rationalised lifestyle through which he has managed to gradually transform his body from that of a skinny young boy into that of a masculine, competitive and grown-up man (cf. [49-51]). This way of presenting oneself in relation to peers and others may, however, be decisive.

It can be contrasted with, for example, the experiences of another informant called William (42-year-old hockey coach and caretaker, in a relationship). Just like Robert, William started to use PES in order to keep up in his comparison with other young men. He started to use PES in his twenties, when he decided to compete in bodybuilding. At that time he was quite thin, and came to realise that he had to engage in drug use practices in order to assert himself in relation to other bodybuilders on a bodybuilding stage. William's story, however, is somewhat different when it comes to the consequences of the drug using practices. At one point, for example, I sat down with William in the locker room after a joint training session. William was on his way to the showers, as he suddenly stopped in front of me and asked, "Hey, have you seen these?" He points at two small scars on each side of his chest, adjacent to his nipples. "They come from an operation for bitch tits, you know" (gynecomastia). After the showers, William brought up the topic again, explaining that at first he thought the drugs were necessary if he wanted any "real results". He never thought much about the 
possible side-effects and the risk of this practice though. And certainly he never wanted to develop what he describes as "women's breasts". He lacked knowledge on how to run a course of treatment in a controlled manner. For example, he was not aware of the existence or need of using estrogen blockers or anti-aromatase drugs that could prevent the aromatisation of excessive testosterone to estrogen that causes the condition here described as "bitch-tits". Consequently, the initial motives for his drug use resulted in feelings of shame, low self-esteem and being less of a man-quite the opposite of what he had hoped to achieve [7,52]. Of course the concept of "bitch tits" and the discussion put forward by William could also be situated within a misogynistic discourse and a cultural landscape of an oppressive and orthodox masculinity [30].

It is not surprising that a lifestyle in which the individual customises his diet, training, and drug regimen, and spends countless hours in the pursuit of the perfect body, also has a deep influence on other aspects of social life, besides possible side-effects of the drugs. Below, Lukas (46-year-old nurse, single) gives an honest description of how problematic it can be to be engaged in drug use and at the same time be in a committed relationship.

"I have this painful memory: my girlfriend is crying and hammering on my chest saying 'I want my old Lukas back'. She saw how I had changed. I was not violent towards her, but she could not really reach me, or affect me. So it has probably been difficult for her. (...) I went behind her back there, so she took it as a huge betrayal. I can understand that" (Lukas).

Turning his focus to training and building up a solid body, Lukas allowed his girlfriend to become less important. She had seen him grow and had for some time been worried about him starting to use PES to accelerate his transformation. Lukas was of course aware that his girlfriend was worried and tried to conceal his involvement. Consequently, when she found out, the treachery was felt to be even greater. This narrative also fits rather neatly into much existing literature on some of the negative effects of steroids and drug use, which have been carefully investigated and analysed, and suggest that the use of PES may cause relationship problems and potentially violent behaviour $(c f$. $[19,41,53])$. Although Lukas declares that his experiences with doping never made him violent, he obviously recognises that the practice did change him, not only in desirable bodily directions [13].

Some of the informants actually had lost control and proposed that their use of PES made them aggressive. Adrian (24-year-old ex-convict, married with two children), for example, told me what happened when his ex-girlfriend was unfaithful. The interview was conducted just after he got out of jail for the situation described below.

"... and then she cheats on me, with my buddy, I mean I was with her for several years. And really, I did anything for her. But then it just turned black and it kind of exploded in my head. So I really beat up my friend, and even her, unfortunately" (Adrian).

Now, looking at the situation at a distance, Adrian can see that his ex-girlfriend's infidelity partly had to do with him becoming something of an unpleasant and controlling person. There is some degree of reflexivity in Adrian's narrative, and the others' narratives presented above. At the same time, however, it is apparent that this kind of domineering masculinity, constructed with the help of PES, certainly seems to have a constant urge to defend and assert itself-sometimes even with fists, as described above - and to rationalise its behaviour. Consequently, these ways of performing masculinity do not seem to bring much of a change in the gender politics associated with fitness doping. That some 
men are willing to use illegal means in order to achieve the right masculine body appearance is indicated by several studies on the prevalence of doping [25,54]. Furthermore, inherent in the narratives are also recurring side-effects in which the desire to continuously develop and become more of a man is countered by the potential risks of consequences opposite to those initially intended, such as loss of control in relationships, over one's own actions and over one's body [53]. In this sense there is a delicate balance between the embodiment of normative gender configurations and the inherent threat of "losing it all" in the pursuit manhood.

\subsection{Negotiating Fitness Doping and the Bodybuilding Body}

Since the 1970s, gym and fitness culture has gone through a remarkable transformation process in which there has been a marked increase in the number of exercise premises presenting themselves in a new guise, focusing on health promotion and a healthy lifestyle in a commercial and individualistic manner ([1], p. 17). The notion of the gym has steadily shifted to represent a mass leisure activity [11]. Consequently, typically masculine competitive activities such as bodybuilding have been increasingly marginalised during this development [1]. One important reason for the cultural separation of the concepts of bodybuilding and fitness is to be found in the frequent reports of drug use among bodybuilders. In the 1990s, bodybuilding acquired a negative reputation, and came to be associated with a defensive and compensatory masculinity [7,53]. Mogensen [40] also shows in a Danish study how fitness franchises sometimes use drug tests and anti-doping campaigns with pictures of bodybuilders, in order to keep a favourable reputation and eliminate bodybuilders from their clientele. Below, Lars (41-yearold teacher, single with one child) tries to explain how he perceives himself. In his story it becomes evident that the identity of the bodybuilder can be highly ambivalent.

"I'm a regular guy who likes to compete in bodybuilding. I think I like doing it and want to continue, but it's not my whole identity, even though I'm immersed in it. But I've always been afraid that people will think that I am violent or something. 'Cause you know that's what the papers say; people think you're totally whacked out, or look down on others'. That you only judge people based on how their body looks. Nah, that's not me. This is something I like to do, and other people can do what they like to do. So I've always been a little afraid that people tend to maybe judge bodybuilders that way" (Lars).

The muscular male body clearly has an ambivalent position in contemporary fitness culture. On the one hand the lifestyle and dedication to the task that Lars's body represents is highly valued, at least on a cultural and symbolic level. Well-developed and muscular bodies are seen as the end-result of hard-core training and diet, and are often displayed in mainstream films as expressing heroic masculinity. On the other hand, however, the bodybuilding body is often associated with drugs, problems in relationships, aggressiveness and the grotesque, as discussed in the preceding section (cf. [11]). Therefore, when positioning himself and his dedication, Lars is clearly careful to project that he is not a freak, an example of what academics have described as "the postmodern pastiche" [55]. He is the reluctant bodybuilder who wants to present himself in a reflexive manner. Consequently, he is making an effort to counter populist and mythical descriptions of bodybuilders and PES users, aiming to widen the stereotypical expectations and conceptions of gender that he thinks are attached to this practice. In the story below, this negotiating stance becomes even more explicit. 
"Right now I'm in pretty decent shape. I am $1.9 \mathrm{~m}$ tall and weigh around 135 kilos, so I guess it is pretty obvious that I have been using. But I can sit down and have a conversation, and show that I'm pretty normal anyway, you know. You sit down and eat a hamburger and pizza and stuff like that. You're not extreme or fanatical when it comes to diet. You can have a beer and still talk about alcohol problems in general, you can talk about the situation in Afghanistan, about gender issues, and things like that" (Ted, 28-year-old unemployed, single).

Aiming to counter the perceived popular wisdom of other people's (imagined) thoughts about PES users, Ted tries to present himself not only as a dedicated gym-goer but also as an intellectual young man. He finds it highly challenging to control how others perceive him and when meeting new people he feels an urge to talk about his university studies and show that he is much more than a solid body (cf. [56]). In some ways this intellectual and reflexive self-portrayal becomes a strategy to counter a stereotypical perception of the bodybuilder as "big muscles, no brain", as Ted expresses it ( $c f$. [45]).

Another informant, Nicholas (35-year-old industrial carpenter, engaged with three children), has rather ambitious goals. He has been competing in bodybuilding for a few years, as a heavyweight. He has no problem looking at himself as first and foremost a bodybuilder. Formulating his approach to the body is initially centred on constructing a long-term solid and highly muscular body, and included in this pursuit are the use of substances such as steroids, human growth hormones, and experimentation with insulin. At the same time, his competitive goals and the different seasons of a bodybuilding lifestyle do not always come easy for him. The longitudinal goals of the training and drug regimen are hard to reconcile with a short-term perspective and an understanding of the self, based on the idea of the beautiful body.

"Like now after my last competition, my coach told me I should probably gain some weight, you know, bulk up during the off-season. But I feel that if I'm going to weigh like 125 kilos I'm going to be really obese. People won't see any difference between me, a bodybuilder, and your average overweight truck driver, and I don't like that. And it's the same before a competition, like on the load-up day. I start at midnight: I get up and eat two burgers with fries and everything. And then I felt like, what the hell am I doing, sitting here wolfing down hamburgers! Because it is a little weird-here I've been eating so healthily for months and suddenly I'm supposed to totally pig out, just to stick to the plan" (Nicholas).

Understanding himself as a healthy young man, Nicholas finds it challenging to justify parts of his diet and body. The focus is on the here and now, on the slender, supple and muscular body that is primed to be put on display every day of the week. Despite the fact that his lifestyle includes quite advanced courses of PES treatments in high doses, there is also an aspect of health being negotiated in this narrative, focusing not on the drug regimen but rather on diet and lifestyle in general. In this way, he is writing his own rules for success and formulating a narrative on how to continuously keep fit and look beautiful. Below, these partly conflicting, and traditionally also highly gender-binary, perspectives on the body seem to merge, as Andrew (59-year-old assistant psychiatric nurse, single) describes his perception of training, beauty, and drugs.

"It was probably the aesthetics and the more symmetrical bodybuilders that inspired me. You know, in beautiful poses and where symmetry and muscle merge into one. It's 
graceful. (...) I'm more for the symmetry aspects, the charisma. Like Bob Paris- he was very symmetrical back in the day. But I guess it was also his physical hardness, which is crucial. Plus there was a bit...not just manufactured in the chemical way, but also an incredible discipline. I mean of course it's there, the drugs - otherwise it would never have come so far. You know, like some people think, 'yeah, yeah but you're just on the steroids'. Well, ok, but it's still a lifestyle" (Andrew).

One way of approaching both Andrew's and Nicholas's narratives would be to read them as a normative masculine construction in which the narrator envisions a bodybuilding icon, from which he motivates himself to construct a similar muscular body. These narratives could thus be read as expressions of a man's determination to follow a strictly defined routine to reach the ultimate goal, which is thus an ideal coinciding with hegemonic masculinity [27]. At the same time, however, there is also a negotiating reflexivity in the comments quoted, in which masculinity is constructed in a more sensual and aesthetic manner, as representing a masculinity defined through beauty, charisma and grace. At stake here is not only what Andrew, for example, wants to create for himself, but also what he finds attractive and impressive. The fascination with Bob Paris's physicality, the person of admiration and the gaze can be read as expressions of how the heterosexual gender power order has come to be questioned. The fact that Andrew mention Bob Paris as a source of inspiration and admiration is also interesting when considering that he was (and is) one of few openly gay-identified bodybuilders, with a high symbolic value in gay gym culture even today. It could be understood as an example of what Nixon ([57], p. 13ff.) describes as a process of cultural transformation in which the bodies of men have come to be sensualised and aestheticised [58]. Following this logic, the intense watching over one's own and other male bodies, the muscles, the shape and the symmetry, could be understood to some extent an expression of curiosity about "the Other". It could be seen as the outcome of an increased awareness that heterosexual men can act in ways once associated with homosexuality, with less of a threat to their public identity as heterosexuals [30]. Furthermore, this way of gazing and (symbolically) sensualising bodies, has traditionally been reserved for the bodies of women, and hence this way of looking upon the body could be understood as a convergence of male and female physicality [1,59].

\subsection{Inclusive Masculinities and the Symbolism of Homoerotic Practices}

In contemporary gym and fitness culture, the muscular body is idealised and idolised as both an aesthetic and an erotic object. Through the pumping of iron, controlled diets, and sometimes comprehensive drug regimens, the image of the perfect body has been partly revered, as it simultaneously symbolises hard work and has become a beauty ideal that awakens desires [1]. Not surprisingly, this cultural transformation process has an effect on how people exercise and how they perceive their muscle-building practices. For example, even though the cultural bond between masculinity and muscles has a long history [47,51], there are also tendencies towards a convergence of masculinity and femininity. For example, having a supple, dynamic and muscular body has become an ideal for both men and women [5,58,60,61]. This convergence is also evident in some of the narratives upon which this article is based. See, for example, the following narrative, given by Ian (37-year-old 
carpenter, engaged), who has long experience of both competitive bodybuilding and the use of PES, as he describes how his perception of gendered bodies manifests itself when he is preparing for a competition.

"You can stand next to the best-looking girl in the world. She could stand there naked even, and you wouldn't see. You don't care either. Like when I'm there it's to be painted, I mean getting your own body tanned or helping someone to put their colour on. So it's a different world somehow. (...) If you look at something, it's more like, 'Damn, she is in good shape!' (laughs) It's more like that" (Ian).

Ian is heterosexually identified, and is currently engaged to a Body Fitness competitor. During the bodybuilding and fitness competition from which this narrative departs, however, the object of his desire and the gender of muscles seem to be more fluid and situational in his mind. For example, he describes a situation backstage in which he stood in front of a completely naked fitness competitive woman engaged in applying bronzers (brown cream) to her inner thighs. His reaction to this "scenery" was, as he described it, focused on her muscle development. His admiration was thus not sexual, but rather focused on something of an evaluation of fitness level and symmetry, with gender being relegated to the background. The situation is of course to be understood contextually, and is to some extent obviously limited to the bodybuilding scene, as Ian is after all engaged to a female fitness competitor. Nevertheless, applying oil and tanning paint closely to another person's intimate body parts backstage of the bodybuilding scene, regardless of sex or sexual preferences, could in this way be seen as an act in which the doped, lean, supple body becomes genderless. It is flesh, beauty, and accomplishment at the same time, but not necessarily connected to a specific sexuality or gender.

The cultural critic Mark Simpson identified what he called the "metrosexual male" in the mid-1990s [62]. What he was trying to describe was a market segment of young urban, predominantly middle-class men preoccupied with appearance, style and image. When introduced, this phenomenon was thought to indicate a movement towards a new masculinity in crisis, and a closer relationship between homo and hetero men ( $c f$. [30]). Situated in a gym and fitness context, Ian's narrative, and certainly the following narrative, would fit neatly into such a conception of how the aesthetic and perfectly moulded masculine body is understood [63].

"But there's this in-betweenness, too, when you talk about it or think about it. It's something not male, but not female either. Or maybe it's gay, actually. Of course you could see it as being quasi-gay" (Alexander, 35-year-old journalist, engaged).

Alexander is here trying to understand, and at the same time problematize, his interest in muscular bodies in relation to his gender identity, using the premise that sexual preference is an important expression of masculinity [64]. In his quest for inspiration, despite heterosexual identified, he often gazes at other men's bodies, their muscular development and the shaping and roundness of different parts of the body. This obviously leads to some reflection and concern. In the following narrative, this way of approaching other men's bodies becomes even more pronounced.

"I think it's a nice feeling. I get so fucking lit. I get turned on when I see people like Joey, when he works out. I really get turned on, well maybe not sexually, but get turned on, on psychological level. I see him. It is when I see that demon, that's when I am turned on." (Les, 44-year-old personal trainer, engaged) 
In Les's narrative, above, the admiration and excitement - the "turn-on"- depart from the complete devotion that his friends manifest when working out. However, it is also a story about how one man looks at another in a sensual manner, finding him attractive and beautiful. Although the turn-on is explicitly said to be non-sexual, clearly this way of approaching another man's body could, however, be said to challenge the kind of orthodox masculinity that otherwise typically surrounds gay athleticism and supports hegemonic constructions $[59,65,66]$. Alexander and Les are to some extent asking themselves if, given their interest in other men's bodies, they are gay. Seemingly, they do not feel obligated to align their social identity with heterosexuality, nor do they seem to think it is important to avoid homosexual suspicion. In this sense the narratives are clearly questioning the compulsory heterosexuality and homophobia that have served as an ordering principle in many Western cultures, particularly in sports $([7,30,67]$. Therefore, on a symbolic level there is a highly inclusive and also subversive potential in the perspective (read: masculinity) put forward here, in which the muscle-building becomes a kind of a motor for changed perspectives in the realm of sexual politics and the questioning of traditional categories of sexual orientation ([62], p. 197).

\section{Conclusions}

In this article, I have used an empirical material building upon the narratives of gym-goers, predominantly bodybuilders, with personal experience of drug use practises in a gym and fitness context. The narratives and self-representations analysed in the article can clearly be understood in different ways. In the results, however, three distinct and differentiated interpretations of masculinity in relation to fitness doping emerge. These different positions and ways of doing gender and drugs are not, however, to be understood as inherently exclusive, in the sense that one individual can easily be categorised within only one position/interpretation. Individuals are not one-dimensional; hence, each narrative can, in a variety of ways, bear traces of all three of these positions ([68], p. 158).

The first position, which has been thoroughly described and analysed in the existing literature, could be described as a complicit position in relation to hegemonic masculinity. For example, a common feature of many of the narratives presented regarding ways of approaching illegal substances such as steroids and human growth hormones is the underlying idea that the idealised male body can be achieved through continuous effort and with the help of PES. Such a masculinity, constructed in the realm of performance, could clearly be related to a normative masculine stereotype, shaped by traditionalism. Although expressed differently, the overall perspective on masculinity and fitness doping put forward through this position rests heavily on a binary understanding of gendered bodies, doping, and competences, in which the female body is viewed as weak and the male body strong and competent. Hence drug-use practices are constructed as a male phenomenon and a booster for masculinity, more or less solely. Consequently this position situates the bodies of men as inevitably superior to women within gym culture and society in general and fitness doping in particular.

The second position that emerges could be described as a negotiating position. On the one hand, this position shows a clear tendency toward complicit masculinities. On the other hand, it also points in the direction of the transformation of gender configurations and the sexual politics of fitness doping. In many of the narratives that can be situated within this position the trajectories to drug use seem to originate in quite hegemonic conceptions, such as being motivated by homosocial relationships, etc. However, at the same time when reading the narratives, it becomes obvious that such an interpretation 
is incapable of capturing the whole presentations of self put forward, and that the narratives clearly have more nuances. These intertwined tendencies are clear when looking at the ways in which some informants try to "rewrite" and respond to actual or imagined questioning of their lifestyle choices. They can be seen in the different ways in which the muscular male body and the beautiful body is explored. They are also manifested in the ways in which the use of PES is integrated with the concept of health and intellectualism, extending the notion of masculinity and fitness doping in alternative directions.

Finally, we have a more inclusive and potentially subversive position in which fitness doping is renegotiated in relation to the body and heteronormativity [30]. This position emerges in the ways in which the informants, regardless of their sexual preferences, can be close to other men and their bodies in a more sensualised, aestheticising manner. Through drug-use practices the focus is so vividly placed on the characteristics and shape of the body that, paradoxically, the body itself becomes to some extent detached from sex/gender. The physicality becomes more important than sexual orientation, which makes it possible for the informants to express emotions and values that traditionally have been associated solely with femininity and/or homosexuality. Consequently, this way of approaching the male body may actually contribute to an increased acceptance of, for example, gay identities or other submissive positions. This approach and position therefore amount to a contestation of hegemonic gender values, in which masculinity and fitness doping have become detached from a solidly heterosexist understanding and turned into inclusiveness and perhaps also a homoerotic pleasure, at least on a symbolic level.

In summary, within the field of fitness doping it is possible to identify and explore different ways of doing and (re)presenting masculinity. In some narratives there is clearly a strong tendency to comply with and adjust to certain gender fantasies in relation to this practice; however, challenges to hegemonic masculinity are also being expressed [29]. Some of the narratives presented clearly emphasise alternative ways of performing masculinity in relation to fitness doping, thus indicating possible changes to our understanding of hegemonic masculinity. Although this article is mainly theoretically informed and builds upon the narratives of a few, it nevertheless identifies the strong need for future research on fitness doping in relation to gender and sexuality. For instance, in addition to continuing the exploration of how this practice might be categorised and understood within the three positions discussed above, there is of course also a great need to identify other ways of approaching and understanding the gender of fitness doping, not least by analysing narratives of female users.

\section{Conflicts of Interest}

The author declares no conflict of interest.

\section{References}

1. Roberta Sassatelli. Fitness Culture: Gyms and the Commercialisation of Discipline and Fun. London: Palgrave MacMillan, 2010.

2. Michael A. Budd. The Sculpture Machine: Physical Culture and Body Politics in the Age of Empire. London: MacMillan Press, 1997.

3. George L. Mosse. The Image of Man: The Creation of Modern Masculinity. New York and Oxford: Oxford University Press, 1996. 
4. Kenneth R. Dutton. The Perfectible Body: The Western Ideal of Physical Development. London: Cassell, 1995.

5. Thomas Johansson. "Gendered spaces: The gym culture and the construction of gender." Young 4 (1996): 32-47.

6. Thomas Johansson. Den Skulpterade Kroppen: Gymkultur, Friskvård och Estetik (The Sculpted Body: Gym Culture, Wellness and Aesthetics). Stockholm: Carlsson Bokförlag, 1998.

7. Alan M. Klein. Little Big Men: Bodybuilding, Subculture and Gender Construction. New York: State University of New York Press, 1993.

8. John Evans, Brian Davies, and Emma Rich. "The body made flesh: Embodied learning and the corporeal device." British Journal of Sociology of Education 30 (2009): 391-406.

9. Christina Hedblom. The Body Is Made to Move-Gym and Fitness Culture in Sweden. Stockholm: Acta Universitatis Stockholmiensis, 2009.

10. Cecil G. Helman. Culture, Health and Illness, 5th ed. London: Hodder Education, 2007.

11. Adam Locks, and Niall Richardson. Critical Readings in Bodybuilding. New York: Routledge, 2012.

12. Shelly McGrath, and Ruth Chananie-Hill. “'Big Freaky-Looking Women': Normalizing Gender Transgression through Bodybuilding." Sociology of Sport Journal 26 (2009): 235-54.

13. Lee F. Monaghan. Bodybuilders Drugs and Risk (Health, Risk and Society). New York: Routledge, 2001.

14. Inge Kryger-Pedersen. "Doping and the perfect body expert: Social and cultural indicators of performance-enhancing drug use in Danish gyms." Sport in Society 13 (2010): 503-16.

15. Charles Yesalis, and Michael Bahrke. "Anabolic Steroid and Stimulant Use in North American Sport between 1850 and 1980." In Drugs, Alcohol and Sport. Edited by Paul Dimeo. New York: Routledge, 2007.

16. Jean Bilard, Gregory Ninot, and Denis Hauw. "Motives for illicit use of doping substances among athletes calling a national antidoping phone-help service: An exploratory study." Substance Use \& Misuse 46 (2011): 359-67.

17. Gen Kanayama, and Harrison G. Pope. "Illicit use of androgens and other hormones: Recent advances." Current Opinion in Endocrinology, Diabetes and Obesity 19 (2012): 211-19.

18. Tonya Dodge, and James Jaccards. "The Effect of High School Sports Participation on the Use of Performance-Enhancing Substances in Young Adulthood." Journal of Adolescent Health 39 (2006): 367-73.

19. Robert H. DuRant, Luis G Escobedo, and Gregory W. Heath. "Anabolic-Steroid Use, Strength Training, and Multiple Drug Use among Adolescents in the United States." Pediatrics 96 (1995): 23-29.

20. Perikles Simon, Heiko Striegel, Fabian Aust, Klaus Dietz, and Rolf Ulrich. "Doping in fitness sports: Estimated number of unreported cases and individual probability of doping." Addiction 101 (2006): 1640-44.

21. Paul Dimeo. A History of Drug Use in Sport 1876-1976: Beyond Good and Evil. London and New York: Routledge, 2007.

22. Andrew B. Parkinson, and Nick A. Evans. "Anabolic androgenic steroids: A survey of 500 users." Medicine and Science in Sport and Exercise 38 (2006): 644-51. 
23. Krzysztof Sas-Nowosielski. "The abuse of anabolic-androgenic steroids by Polish school-aged adolescents." Biology of Sport 23 (2006): 225-35.

24. Donald R. McCreary, Thomas B. Hildebrandt, Leslie J. Heinberg, Michael Boroughs, and J. Kevin Thompson. “A Review of Body Image Influences on Mens's Fitness Goals and Supplement Use.” American Journal of Men's Health 4 (2007): 307-16.

25. Nicole Thualagant. "The Conceptualization of Fitness Doping and Its Limitations." Sport in Society: Cultures Commerce Media Politics 15 (2012): 409-19.

26. Raewyn Connell. Gender \& Power. Cambridge: Polity Press, 1987.

27. Raewyn Connell. Masculinities. Cambridge: Polity Press, 1995.

28. Raewyn Connell, and James W. Messerschmidt. "Hegemonic masculinity: Rethinking the concept." Gender \& Society 19 (2005): 829-59.

29. Jesper Andreasson, and Thomas Johansson. "Female Fitness in the Blogosphere: Gender, Health, and the Body." Sage Open, 2013. doi:10.1177/2158244013497728.

30. Eric Anderson. Inclusive Masculinities: The Changing Nature of Masculinities. London: Routledge, 2009.

31. Ann-Dorte Christensen, and Sune Qvotrup Jensen. "Combining hegemonic masculinity and intersectionality." NORMA: International Journal for Masculinity Studies 9 (2014): 60-75.

32. Judith Butler. Gender Trouble Feminism and the Subversion of Identity. London: Routledge, 1990.

33. Jeff Hearn. "From hegemonic masculinity to the hegemony of men." Feminist Theory 5 (2004): 49-72.

34. Richard Howson. Challenging Hegemonic Masculinity. London: Routledge, 2006.

35. Nikki Wedgwood. "Connell's theory of masculinity - Its origin and influences in the study of gender." Journal of Gender Studies 18 (2009): 329-39.

36. Jesper Andreasson. "Between Beauty and Performance: Towards a sociological understanding of trajectories to drug use in a gym and bodybuilding context." Scandinavian Sport Studies Forum 4 (2013): 60-90.

37. Martyn Hammersley, and Paul Atkinson. Ethnography: Principles in Practice. London: Routledge, 1995.

38. Chris Gratton, and Ian Jones. Research Methods for Sport Studies. London: Routledge, 2004.

39. Katrine Fangen. Deltagande Observation (Participant Observation). Malmö: Liber, 2005.

40. Kevin Mogensen. Body Punk En Afhandling om Mandlige Kropsbyggere og Kroppens Betydninger i lyset av Antidoping Kampagner (Body Punk. A Thesis on Male Bodybuilders and the Meanings of the Body in the Light of Anti-Doping Campaigns). Roskilde: Roskilde Universitetscenter, 2011.

41. Alice Riis Bach. Moend och Muskler-En bog om Stryketcening og Anabole Steroider (Men and Muscles-A Book about Weight Lifting and Anabolic Steroids). København: Tiderna skifter, 2005.

42. Philip Lalander. Hooked on Heroin: Drugs and Drifters in a Globalized World. Oxford and New York: Berg Publishers, 2003.

43. Michael Agar. Professional Stranger: Informal Introduction to Ethnography. London: Emerald Group, 1996.

44. Pierre Bourdieu, and Loïc J. D. Wacquant. An Invitation to Reflexive Sociology. Cambridge: Polity Press, 1992. 
45. Beverly Skeggs. Formations of Class and Gender: Becoming Respectable. London: SAGE Publications, 1997.

46. Steve Robertson. Understanding Men and Health: Masculinities, Identity and Well-Being. Berkshire: Open University Press, 2007.

47. Michael S. Kimmel. Manhood in America: A Cultural History. New York: The Free Press, 1996.

48. Yvonne Tasker. Spectacular Bodies. Gender, Genre and the Action Cinema. New York: Routledge, 1993.

49. Nils Hammarén, and Thomas Johansson. "Homosociality: In Between Power and Intimacy." SAGE Open 4 (2014): 1-11.

50. Brian Pronger. The Arena of Masculinity: Sports, Homosexuality, and the Meaning of Sex. New York: St. Martin's, 1990.

51. Michael Messner. Power at Play: Sports and the Problem of Masculinity. Boston: Beacon Press, 1992.

52. Andrew C. Sparkes, Joanne Batey, and Gareth J. Owen. "The Shame-Pride-Shame of the Muscled Self in Bodybuilding." In Critical Readings in Bodybuilding. Edited by Adam Locks and Niall Richardson. New York: Routledge, 2012.

53. Bryan E. Denham. "Masculinities in hardcore bodybuilding." Men and Masculinities 11 (2008): 234-42.

54. Ask Vest Christiansen. "Doping in fitness and strength training environments-Politics, Motives and Masculinity." In Elite Sport, Doping and Public Health. Edited by Verner Møller, Mike McNamme and Paul Dimeo. Odense: University Press of Southern Denmark, 2009.

55. Barry Glassner. "Fit for Postmodern Selfhood." In Symbolic Interaction and Cultural Studies. Edited by Howard S. Becker and Michael McCall. Chicago: The University of Chicago Press, 1990, pp. 215-43.

56. Pierre Bourdieu. Distinction: A Social Critique of the Judgement of Taste. London: Routledge, 1984.

57. Sean Nixon. Hard Looks: Masculinities, Spectatorship \& Contemporary Consumption. London: UCL Press, 1996.

58. Deana A. Rohlinger. "Eroticizing Men: Cultural Influences on Advertising and Male Objectification." Sex Roles 46 (2002): 61-74.

59. Pirkko Markula. "Beyond the Perfect Body: Women's Body Image Distortion in Fitness Magazine Discourse.” Journal of Sport and Social Issues 25 (2001): 158-79.

60. Susan Bordo. "Reading the slender body." In Body/Politics Women and the Discourse of Science. Edited by Mary Jacobus, Evelyn Fox Keller and Sally Shuttleworth. London: Routledge, 1990.

61. Nancy Malcolm. "Constructing Female Athleticism: A Study of Girls Recreational Softball." American Behavioral Scientist 46 (2003): 1387-404.

62. David Coad. The Metrosexual: Gender, Sexuality, and Sport. New York: Sunny Press, 2008.

63. Matthew Hall, Brendan Gough, and Sarah Seymour-Smith. "I'm METRO, NOT Gay!': A Discursive Analysis of Men's Accounts of Makeup Use on YouTube." The Journal of Men's Studies 3 (2012): 209-26.

64. Jeffrey Fracher, and Michael Kimmel. "Hard issues and soft spots: Counselling men about sexuality.” In Men's Lives. Edited by Michael Kimmel and Michael Messner. Boston: Allyn and Bacon, 1995. 
65. Eric Anderson. "Openly gay athletes: Contesting Hegemonic Masculinity in a Homophobic Environment." Gender \& Society 16 (2002): 860-77.

66. Lisa Wolf Wendel, J. Douglas Toma, and Christopher Morphew. "How much difference is too much difference? Perceptions of gay men and lesbians in intercollegiate athletics." Journal of College Student Development 42 (2001): 465-79.

67. David C. Plummer. One of the Boys: Masculinity, Homophobia and Modern Manhood. New York: Harrington Park Press, 1999.

68. Rosi Braidotti. Nomadic Subjects: Embodiment and Sexual Difference in Contemporary Feminist Theory. New York: Columbia University Press, 1994.

(C) 2015 by the author; licensee MDPI, Basel, Switzerland. This article is an open access article distributed under the terms and conditions of the Creative Commons Attribution license (http://creativecommons.org/licenses/by/4.0/). 